\title{
An in situ and ultrasound study of Yonaguni ponies revealed the rare finding of the nuchal ligament lamellae from C2-C7
}

\author{
Sharon MAY-DAVIS ${ }^{1 *}$, Fumiko MINOWA ${ }^{2}$ and Wendy Y. BROWN ${ }^{1}$ \\ ${ }^{1}$ University of New England, Canine and Equine Research Group, Armidale 2350, Australia \\ ${ }^{2}$ Minowa Horse Clinic Co., Ltd., Tokyo 144-0033, Japan
}

The Yonaguni pony is a rare breed of pony that has remained isolated on the westernmost island of Japan and may well retain normal morphological traits currently lost in most domestic horses (Equus caballus), such as the attachment of the nuchal ligament lamellae (NLL) from C2-C7. Recent research has found that NLL attachments are no longer present at $C 6$ and $C 7$ in most modern domesticated horses. This study investigated the attachments of the NLL in three Yonaguni ponies; 2 were examined in situ(deceased), and 1 was examined in vivo via ultrasound. The aim was to verify the attachments and compare the morphology to that in equids from previous studies. The in situ (2/2) and in vivo (1/1) findings revealed that the NLL was attached from $C 2-C 7$ in the Yonaguni ponies.

Key words: cervical vertebrae, nuchal ligament lamellae, ultrasound, Yonaguni pony

\author{
J. Equine Sci. \\ Vol. 31, No. 4 \\ pp. 93-94, 2020
}

The Yonaguni pony has been the sole equid to have inhabited the westernmost island of Japan (Yonaguni), and as a rare, isolated breed of pony it may still retain morphological traits predominantly lost or reduced in domestic horses (Equus caballus) [4, 6]. Of particular interest is the reduction in the number of nuchal ligament lamellae (NLL) attachments to the cervical vertebrae, with the previously reported normal of NLL attachments at $\mathrm{C} 2-\mathrm{C} 7$ now reduced to NLL attachments at $\mathrm{C} 2-\mathrm{C} 5[1,3]$. However, the normal number of attachments from $\mathrm{C} 2-\mathrm{C} 7$ has been reported in Equus asinus, Equus przewalskii, Equus quagga boehmi and close descendants of Equus ferus ferus [3]. Therefore, the aim of this study was to investigate the NLL attachments at $\mathrm{C} 6$ and $\mathrm{C} 7$ in the Yonaguni pony and compare the morphology between it and four aforementioned species of Equus.

This research was conducted on Yonaguni Island after obtaining approval of its animal ethics from the University of New England (Authority No. AEC19-103). No equids were euthanized for this study. Two deceased Yonaguni ponies were acquired from Yonaguni Island's North Ranch

Received: May 19, 2020

Accepted: August 6, 2020

*Corresponding author. e-mail: maydavis@bigpond.com (C2020 Japanese Society of Equine Science

This is an open-access article distributed under the terms of the Creative Commons Attribution Non-Commercial No Derivatives (by-nc-nd) License. (CC-BY-NC-ND 4.0: https://creativecommons.org/licenses/ by-nc-nd/4.0/) for in situ examinations for NLL attachments to C6 and C7, which were performed by Sharon May-Davis (first author). A single Yonaguni pony, a 3-year-old filly owned by Yonaguni Island Horseback Riding, was used for in vivo examination of the NLL by ultrasonography.

The ultrasound machine was a diagnostic unit (Esaote, Genova, Italy) programmed by MyLab ${ }^{\mathrm{TM}}$ OneVET with a 3-7 MHz convex transducer probe. This transducer probe is suitable for abdominal scanning in large companion animals. The protocols for handling, cleaning and ultrasonic imaging of the Yonaguni pony followed the protocols established by May-Davis, Gee and Brown (2020) [2]. Ultrasonography was performed by Fumiko Minowa (second author). Photographs and ultrasonic images were recorded.

Upon examination of the 2 in situ specimens, dehydrated attachments of the NLL to the dorsal spines of C6 and C7 were recorded. Although the fibres of the NLL were incomplete, there remained clear evidence of the attachments to C6 and C7. In one specimen, remnants of the attachment of the NLL to C6 were damaged close to the dorsal spine, and a $150 \mathrm{~mm}$ cord cord-like attachment to the dorsal spine of $\mathrm{C} 7$ was noted. In the other specimen, remnants of the attachment of the NLL to C6 were broken, and there was a slightly detached cranial attachment to C6 that was $20 \mathrm{~mm}$ in length; there was also a $50 \mathrm{~mm}$ cord-like attachment to C7 (Fig. 1).

Ultrasound images displayed the NLL with reasonable clarity at the level of $\mathrm{C} 5$ and $\mathrm{C} 6$, including the apertures between the attachments of the NLL to their respective 


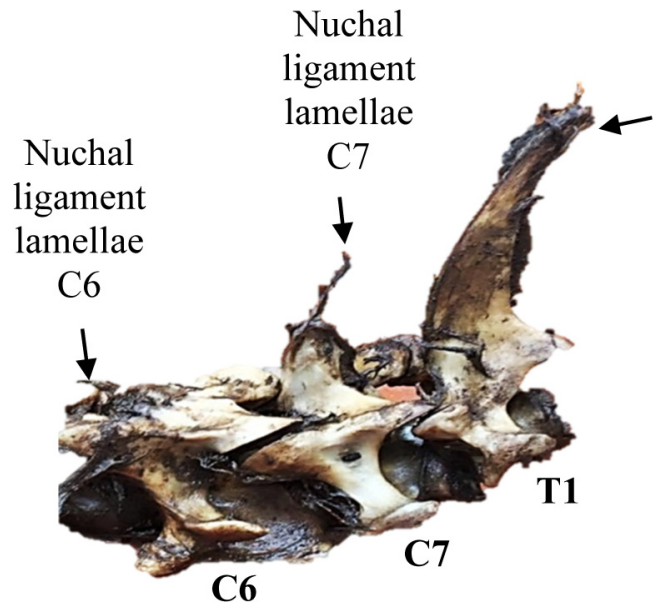

Dorsal
spine
T1

Fig. 1. Remnants of the nuchal ligament lamellae attachments to the dorsal spines of $\mathrm{C} 6$ and $\mathrm{C} 7$. There is a cranially displaced remnant of the nuchal ligament lamellae (NLL) attached to C6.

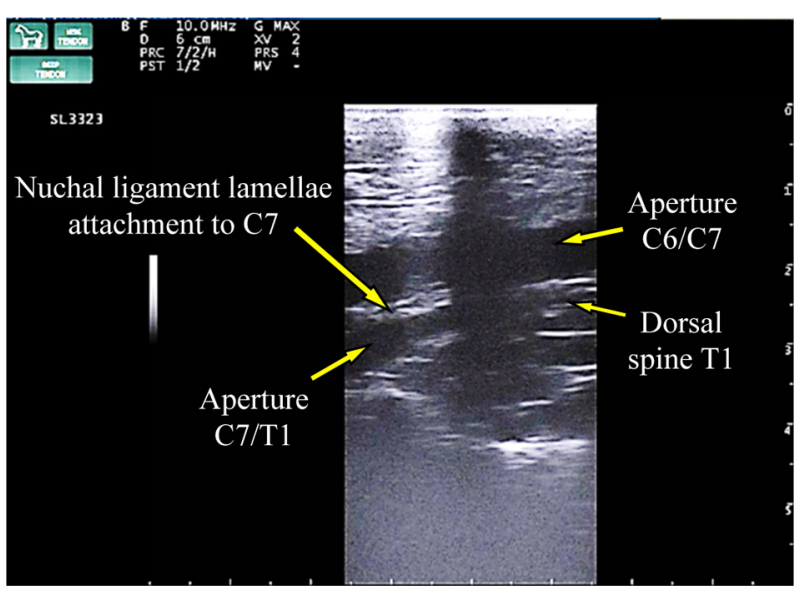

Fig. 3. Ultrasound image of the $\mathrm{C} 6 / \mathrm{C} 7$ and $\mathrm{C} 7 / \mathrm{T} 1$ apertures and the nuchal ligament lamellae attachment to $\mathrm{C} 7$.

vertebrae in the live specimen (Fig. 2).

With the transducer probe angled obliquely, the echogenicity of the NLL at C7 appeared higher than at C5/C6 and displayed elongated apertures (Fig. 3).

Previously, the attachments of the NLL to C6 and C7 have only been examined via dissection in domestic horse breeds $[1,3]$, whereas in this report, the same NLL attachments were revealed in two specimens of Yonaguni ponies in situ and one specimen in vivo. This is considered a rare finding in domestic breeds, and heritability, small island isolation and the lack of external dilution of the Yonaguni pony are plausible factors likely responsible for the preservation of these attachments when compared with domestic horse

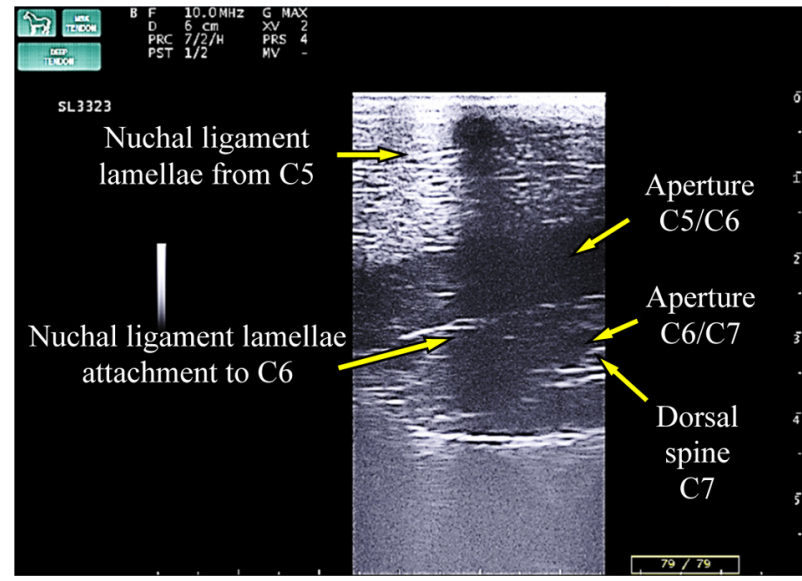

Fig. 2. Ultrasound image of the nuchal ligament lamellae attached to $\mathrm{C} 6$, the $\mathrm{C} 5 / \mathrm{C} 6$ aperture and the dorsal spine of $\mathrm{C} 7$.

breeds [4-6]. The results suggest that ultrasound provides a suitable and non-invasive alternative to investigating the prevalence of NLL attachments on C6 and C7 in a breed, including the extent of this rare finding in Yonaguni ponies.

\section{References}

1. May-Davis, S., Brown, W., and Vermeulen, Z. 2018. The disappearing lamellae: implications of new findings in the family Equidae suggest the loss of nuchal ligament lamellae on $\mathrm{C} 6$ and $\mathrm{C} 7$ occurred after domestication. J. Equine Vet. Sci. 68: 108-114. [Medline] [CrossRef]

2. May-Davis, S., Gee, C., and Brown, W.Y. 2020. Evaluating ultrasound as a non-invasive technique for investigating anatomical variations of the equine nuchal ligament lamellae. J. Equine Vet. Sci. 90: 103017. [Medline] [CrossRef]

3. May-Davis, S., and Kleine, J. 2014. Variations and implications of the gross anatomy in the equine nuchal ligament lamellae. J. Equine Vet. Sci. 34: 1110-1113. [CrossRef]

4. Senju, N., Tozaki, T., Kakoi, H., Matsuyama, R., Nakamura, K., and Takasu, M. 2018. Genetic relationship between Miyako and Yonaguni horses native to Okinawa based on polymorphisms of microsatellites. J. Equine Sci. 29: 87-90. [Medline] [CrossRef]

5. Senju, N., Tozaki, T., Kakoi, H., Shinjo, A., Matsuyama, R., Almunia, J., and Takasu, M. 2017. Genetic diversity of the Yonaguni horse based on polymorphisms in microsatellites and mitochondrial DNA. Theriogenology 79: 425-431. [Medline]

6. Tozaki, T., Takezaki, N., Hasegawa, T., Ishida, N., Kurosawa, M., Tomita, M., Saitou, N., and Mukoyama, H. 2003. Microsatellite variation in Japanese and Asian horses and their phylogenetic relationship using a European horse outgroup. J. Hered. 94: 374-380. [Medline] [CrossRef] 